\title{
Peak fat oxidation is positively associated with vastus lateralis CD36 content, fed-state exercise fat oxidation, and endurance performance in trained males
}

\author{
Ed Maunder ${ }^{1}$ D Daniel J. Plews ${ }^{1} \cdot$ Gareth A. Wallis ${ }^{2} \cdot$ Matthew J. Brick $^{3} \cdot$ Warren B. Leigh ${ }^{3} \cdot$ Wee-Leong Chang ${ }^{4}$. \\ Tom Stewart ${ }^{1,5} \cdot$ Casey M. Watkins ${ }^{1} \cdot$ Andrew E. Kilding ${ }^{1}$
}

Received: 29 April 2021 / Accepted: 21 September 2021 / Published online: 25 September 2021

(c) The Author(s), under exclusive licence to Springer-Verlag GmbH Germany, part of Springer Nature 2021

\begin{abstract}
Purpose Whole-body fat oxidation during exercise can be measured non-invasively during athlete profiling. Gaps in understanding exist in the relationships between fat oxidation during incremental fasted exercise and skeletal muscle parameters, endurance performance, and fat oxidation during prolonged fed-state exercise.

Methods Seventeen endurance-trained males underwent a (i) fasted, incremental cycling test to assess peak whole-body fat oxidation (PFO), (ii) resting vastus lateralis microbiopsy, and (iii) 30-min maximal-effort cycling time-trial preceded by 2-h of fed-state moderate-intensity cycling to assess endurance performance and fed-state metabolism on separate occasions within one week.

Results PFO $\left(0.58 \pm 0.28 \mathrm{~g} \cdot \mathrm{min}^{-1}\right)$ was associated with vastus lateralis citrate synthase activity $\left(69.2 \pm 26.0 \mu \mathrm{mol} \cdot \mathrm{min}^{-1} \cdot \mathrm{g}^{-1}\right.$ muscle protein, $r=0.84,95 \% \mathrm{CI} 0.58,0.95, P<0.001)$, CD36 abundance $\left(16.8 \pm 12.6 \mu \mathrm{g} \cdot \mathrm{g}^{-1}\right.$ muscle protein, $r_{s}=0.68,95 \%$ CI $0.31,1.10, P=0.01)$, pre-loaded 30 -min time-trial performance $(251 \pm 51 \mathrm{~W}, r=0.76,95 \%$ CI $0.40,0.91, P=0.001$; $\left.3.2 \pm 0.6 \mathrm{~W} k g^{-1}, r=0.62,95 \% \mathrm{CI} 0.16,0.86, P=0.01\right)$, and fat oxidation during prolonged fed-state cycling $(r=0.83,95 \%$ CI $0.57,0.94, P<0.001$ ). Addition of PFO to a traditional model of endurance (peak oxygen uptake, power at $4 \mathrm{mmol} \cdot \mathrm{L}^{-1}$ blood lactate concentration, and gross efficiency) explained an additional $2.6 \%$ of variation in 30 -min time-trial performance (adjusted $R^{2}=0.903$ vs. 0.877 ).

Conclusion These associations suggest non-invasive measures of whole-body fat oxidation during exercise may be useful in the physiological profiling of endurance athletes.
\end{abstract}

Keywords Fat metabolism $\cdot$ Cycling $\cdot$ Muscle $\cdot$ CD36 $\cdot$ Performance

Abbreviations

Communicated by Kirsty Elliott sale.

Ed Maunder

ed.maunder@aut.ac.nz

1 Sports Performance Research Institute New Zealand, Auckland University of Technology, Auckland, New Zealand

2 School of Sport, Exercise, and Rehabilitation Sciences, University of Birmingham, Birmingham, UK

3 Orthosports North Harbour, AUT Millennium, Auckland, New Zealand

4 Faculty of Health and Environmental Sciences, Auckland University of Technology, Auckland, New Zealand

5 Human Potential Centre, School of Sport and Recreation, Auckland University of Technology, Auckland, New Zealand

\begin{tabular}{|c|c|}
\hline \multicolumn{2}{|c|}{ Abbreviations } \\
\hline AIC & Akaike information criterion \\
\hline CD36 & Cluster of differentiation 36 \\
\hline $\mathrm{CHO}$ & Carbohydrate \\
\hline CPT1B & Carnitine palmitoyltransferase $1 \mathrm{~B}$ \\
\hline $\mathrm{CV}$ & Coefficient of variation \\
\hline $\mathrm{CS}$ & Citrate synthase \\
\hline FABPpm & $\begin{array}{l}\text { Membrane-associated fatty acid-binding } \\
\text { protein }\end{array}$ \\
\hline GE & Gross efficiency \\
\hline NEFA & Non-esterified fatty acids \\
\hline OXPHOS & Oxidative phosphorylation complex \\
\hline PFO & Peak fat oxidation \\
\hline $\mathrm{TT}$ & Time-trial \\
\hline$\dot{\mathrm{VE}} \dot{\mathrm{VCO}}_{2}^{-1}$ & Ventilatory equivalent for carbon dioxide \\
\hline$\dot{\mathrm{VE}} \cdot \dot{\mathrm{VO}}_{2}^{-1}$ & Ventilatory equivalent for oxygen \\
\hline$\dot{\mathrm{VO}}_{2}$ peak & Peak rate of oxygen consumption \\
\hline
\end{tabular}



$\mathrm{VT}_{1}$
First ventilatory threshold
$\mathrm{VT}_{2}$
Second ventilatory threshold

\section{Introduction}

Non-invasive estimates of whole-body peak fat oxidation rate (PFO) during incremental exercise can be obtained as part of physiological profiling assessments in endurance sport (Maunder et al. 2018b). However, the utility of PFO estimates for gaining insight into skeletal muscle characteristics, fuel utilisation responses during training and competition, and performance in long-duration events in which glycogen stores may become limiting are not well-established.

Associations have been observed between PFO and various skeletal muscle characteristics, including type I fibre percentage and capillary density, mitochondrial protein content and enzyme activities, and enzymes involved in $\beta$-oxidation and intramuscular triacylglycerol hydrolysis (Nordby et al. 2006; Stisen et al. 2006; Dandanell et al. 2018; Shaw et al. 2020). Abundance of fatty acid transport proteins membrane-associated fatty acid-binding protein (FABPpm) and carnitine palmitoyltransferase 1B (CPT1B) have been associated with PFO (Chrzanowski-Smith et al. 2021). However, the relationship between PFO and abundance of fatty acid transport protein cluster of differentiation 36 (CD36) has not been assessed. Abundance of CD36 may be an influential determinant of PFO given whole-muscle and mitochondrial CD36 abundance increased in response to exercise training concomitant with increased whole-body fat oxidation during exercise (Talanian et al. 2010). Therefore, assessing the association between PFO and CD36 abundance has implications for further understanding the metabolic regulation of PFO.

Relationships between fat oxidation and endurance performance have been proposed, but not well established in original research (Maunder et al. 2018a). One laboratorybased study in which dietary macronutrient composition was manipulated indicated a possible influence of PFO on $100-\mathrm{km}$ cycling time-trial performance, though this was not statistically significant (Rowlands and Hopkins 2002). Weak associations between PFO during fasted incremental cycling and endurance performance in field-based, multisport events have been observed, although between-subject pre- or during-competition controls were not employed (Frandsen et al. 2017; Vest et al. 2019). As fat oxidation is influenced by feeding status (Coyle et al. 1997; Horowitz et al. 1997; Bergman and Brooks 1999), and increases over time during prolonged exercise (Ahlborg et al. 1974; Watt et al. 2002, 2006), PFO measured during fasted, incremental exercise may not reflect metabolic responses to the prolonged, fed-state exercise typically performed in competition. Indeed, relationships between PFO and fat oxidation during prolonged, fed-state exercise are poorly understood. Investigating these associations may provide insight into the utility of PFO as a routine measurement in endurance sport.

Therefore, the aim of the present investigation was to assess relationships between PFO measured during fasted incremental cycling, skeletal muscle CD36 abundance, endurance performance, and fat oxidation rates during prolonged moderate-intensity fed-state exercise. A second aim was to determine if inclusion of PFO improves models of endurance performance. We hypothesised PFO would be positively related to skeletal muscle CD36 abundance, endurance performance, and fat oxidation rates during prolonged moderate-intensity fed-state exercise, and that addition of PFO to a model containing peak oxygen uptake ( $\dot{\mathrm{V}}$ $\mathrm{O}_{2}$ peak), power at $4 \mathrm{mmol} \cdot \mathrm{L}^{-1}$ blood lactate concentration, and gross efficiency would improve model fit.

\section{Methods}

\section{Ethical approval}

This study was performed in accordance with the standards of the Declaration of Helsinki, 2013, and the data presented here were collected as part of a larger study. The Auckland University of Technology Ethics Committee approved all procedures (19/146), and all participants provided written informed consent prior to participation. This study was not registered in a database. Data associated with this study are available from the corresponding author upon reasonable request.

\section{Participants}

Seventeen endurance-trained male cyclists and triathletes took part in the present investigation (age $34 \pm 7$ years; height, $181 \pm 8 \mathrm{~cm}$; body mass, $80.5 \pm 9.6 \mathrm{~kg}$; sum of 8 skinfolds, $71 \pm 29 \mathrm{~mm}$; recent training volume, $8 \pm 2 \mathrm{~h}^{\text {week }}{ }^{-1}$; first ventilatory threshold, $206 \pm 39 \mathrm{~W}$; second ventilatory threshold, $265 \pm 54 \mathrm{~W}$; $\dot{\mathrm{VO}} 2$ peak, $4.3 \pm 0.7 \mathrm{~L} \mathrm{~min}^{-1}$ ). The present study includes pre-intervention data from a prior study of the effects of heat training on endurance performance (Maunder et al. 2021). Due to the onset of a nationwide COVID-19 lock-down, some data from some participants were missed. The actual sample size is indicated in the relevant section. Post hoc statistical power estimates were made for primary outcome measures using the 'pwr' $\mathrm{R}$ package. Using observed correlations, sample sizes, and an alpha-level of 0.05 for relationships between observed PFO and CD36 abundance, fat oxidation during prolonged fedstate exercise, and pre-loaded 30-min time-trial performance (W), achieved power estimates were $0.77,0.99$, and 0.94 , 
respectively. This study was conducted during a maintenance phase of training in all participants.

\section{Study design}

A cross-sectional design was used in the present investigation. Participants visited the laboratory on three occasions, $48 \mathrm{~h}$ apart, for an: (i) incremental cycling test after an overnight fast, (ii) resting muscle microbiopsy, and (iii) endurance performance assessment. The order of visits was not randomised as the incremental test data were used to define the power output during the pre-load phase prior to the time-trial in the endurance performance assessment.

\section{Incremental cycling test}

Participants arrived for the incremental cycling test at 07:00 having fasted overnight and refrained from alcohol consumption and vigorous exercise for $24 \mathrm{~h}$. Height and body mass were recorded. Cycling then commenced at $95 \mathrm{~W}$, with the power output increasing by $35 \mathrm{~W}$ every $3 \mathrm{~min}$ (Excalibur Sport, Lode, Groningen, NET). Expired gases were collected throughout (TrueOne2400, ParvoMedics, Sandy, UT, US), and the last minute at each power output was used to estimate whole-body carbohydrate (CHO) and fat oxidation rates, and energy expenditure, using standard non-protein stoichiometric equations (Jeukendrup and Wallis 2005). The PFO was identified as the highest observed rate of whole-body fat oxidation during the incremental cycling test (Achten et al. 2002), and using individual fat oxidation vs. power output models obtained via a second-order polynomial function (Frandsen et al. 2019) in R (version 4.0.4) with RStudio (version 1.1463). Gross efficiency was calculated as the percentage of whole-body energy expenditure converted into mechanical work at $165 \mathrm{~W}$ (Moseley and Jeukendrup 2001). A capillary blood sample was obtained from a finger at the end of each 3-min stage and analysed for blood lactate concentration (Lactate Pro 2, Arkray, Tokyo, Japan). When blood lactate concentration was $>4 \mathrm{mmol} \mathrm{L}^{-1}$, the duration at each power output was reduced to $1 \mathrm{~min}$ until volitional exhaustion. Power output at $4 \mathrm{mmol} \cdot \mathrm{L}^{-1}$ blood lactate concentrations were calculated using available software (Lactate Dashboard 1.1.1, https://shiny.fmattioni.me/ lactate/), which hosts $\mathrm{R}$ code for the calculation of lactate threshold parameters described in recent work (Jamnick et al. 2018). The first ventilatory threshold $\left(\mathrm{VT}_{1}\right)$ was estimated as the work rate at which the ventilatory equivalent for oxygen $\left(\dot{\mathrm{VE}}^{\cdot} \mathrm{V}_{\mathrm{O}_{2}}{ }^{-1}\right.$ ) began to increase in the absence of changes in the ventilatory equivalent for carbon dioxide $(\dot{V}$ $\mathrm{E}^{\cdot} \mathrm{V}_{\mathrm{CO}_{2}}{ }^{-1}$ ) (Lucía et al. 2000). The $\dot{\mathrm{VO}}_{2}$ peak was defined as the highest 15 -s oxygen consumption $\left(\mathrm{VO}_{2}\right)$. Following the incremental cycling test, participants performed a self-paced 30-min time-trial (TT) to act as familiarisation prior to the endurance performance assessment. Participants were also provided with 'base' CHO (e.g. pasta, rice, noodles, rolled oats) to provide $1 \mathrm{~g} \mathrm{~kg}^{-1}$ for dinner at 20:00 the evening before, and $1 \mathrm{~g} \mathrm{~kg}^{-1}$ for breakfast $2 \mathrm{~h}$ prior to, the endurance performance assessment, to ensure participants completed the trial in a fed-state. Participants were permitted to add to these 'base' foods at these meals such that total $\mathrm{CHO}$ intake at these two meals combined was $2.5-3.0 \mathrm{~g} \mathrm{~kg}^{-1}$.

\section{Muscle microbiopsy}

Participants arrived at the laboratory $\sim 48 \mathrm{~h}$ following the incremental cycling test at 9:00 having fasted overnight. A muscle microbiopsy was then obtained from the vastus lateralis using the microbiopsy technique (Hayot et al. 2005). Briefly, local anaesthesia was applied to the skin and superficial muscle fascia, after which a microbiopsy needle was inserted into the mid-belly of the vastus lateralis to a depth of $\sim 2 \mathrm{~cm}$ to recover $\sim 15-20 \mathrm{mg}$ of tissue using a springloaded mechanism (14G Ultimate Biopsy Needle, Zamar Care, Croatia). Muscle tissue was immediately frozen using dry ice, and stored at $-80{ }^{\circ} \mathrm{C}$ until further analysis.

\section{Endurance performance assessment}

Participants arrived at the laboratory $\sim 48 \mathrm{~h}$ following the muscle microbiopsy at 08:00, having avoided vigorous exercise in that time, and having had their evening meal at 20:00 the night before, and morning meal $\sim 2 \mathrm{~h}$ beforehand. Sum of eight skinfold thickness was then determined by an International Society of Kinathropometry accredited anthropometrist (triceps brachii, biceps brachii, subscapular, iliac crest, supraspinale, abdominal, anterior thigh, posterior shank).

Cycling then commenced for $2 \mathrm{~h}$ in a temperature-controlled laboratory $\left(18{ }^{\circ} \mathrm{C}\right.$ and $60 \%$ relative humidity) on an ergometer (Excalibur Sport, Lode, Groningen, NET) at $80 \%$ of the power output at $\mathrm{VT}_{1}$. Convective airflow was provided by an industrial fan (FS-75, FWL, Auckland, NZ). Participants consumed $60 \mathrm{~g}^{-1} \mathrm{~h}^{-1}$ of glucose in $7.5 \%$ liquid solutions at 15-min intervals throughout the constant-load phase. Expired gases were collected for 4 min every 15 min using a metabolic cart (TrueOne2400, ParvoMedics, Sandy, UT, US), with the last 3 min of each sample used to estimate whole-body $\mathrm{CHO}$ and fat oxidation rates using standard non-protein stoichiometric equations (Jeukendrup and Wallis 2005). The mean of these values was used to represent prolonged fed-state fat oxidation during the pre-load phase prior to the TT. Upon completion of the 2-h constant-load phase, a 30-min maximal-effort TT was performed (IndoorTrainer, SRM, Jülich, Germany). During the TT participants were blinded to power and HR, but informed of the time remaining every $10 \mathrm{~min}$ and with 5 - and 1-min remaining. 


\section{Muscle analysis}

Frozen muscle samples were rinsed and suspended to $25 \mathrm{mg} \cdot \mathrm{mL}^{-1}$ in cold phosphate-buffered saline, and ground manually using a pre-cooled glass Dounce homogeniser. Homogenate was solubilised with extraction buffer (ab260490, $\mathrm{Abcam}^{\circledR}$ ) to $5 \mathrm{mg} \cdot \mathrm{mL}^{-1}$ and incubated on ice for $20 \mathrm{~min}$ prior to centrifugation at $16,000 \mathrm{~g}$ for $20 \mathrm{~min}$ at $4{ }^{\circ} \mathrm{C}$. Supernatant was extracted and stored at $-80{ }^{\circ} \mathrm{C}$ prior to further analysis. A Bradford assay for sample protein concentration was subsequently performed in duplicate (intra-assay within-standard deviation coefficient of variation [CV], 3.7\%). Briefly, a Coomassie blue $\mathrm{G}$ reagent was added to protein standards and samples, and optical density was measured on a spectrophotometer at 595 nm (ab102535, Abcam $^{\circledR}$ ). Citrate synthase (CS) activity was determined via a kinetic immunocapture assay (ab119692, Abcam $^{\circledR}$ ). Abundance of CD36 was determined via an enzyme-linked immunosorbent assay (ab267614, Abcam $^{\circledR}$ ). These assays were performed using commercially available kits in duplicate according to the manufacturer's instructions on a spectrophotometer (Multiskan GO, Thermo Fisher Scientific Inc., Porto Salvo, POR). Achieved intra-assay CVs were 5.6\% for CS activity and $9.8 \%$ for CD36 concentration, both expressed relative to total muscle protein concentration.

\section{Statistical analysis}

Sample data are expressed mean \pm standard deviation. The PFO and fat oxidation during prolonged moderateintensity exercise was compared using a paired $t$ test. Relationships between PFO, fat oxidation during prolonged moderate-intensity exercise, vastus lateralis CS activity, and 30-min TT performance (expressed in absolute [W] and relative [W/ $\left.\mathrm{kg}^{-1}\right]$ units) were assessed using Pearson's product-moment correlation coefficients $(r)$. A Grubb's test revealed a significant outlier for vastus lateralis CD36 abundance $\left(52.0 \mu \mathrm{g} \cdot \mathrm{g}^{-1}\right.$ muscle protein, $\left.Z=2.656, P<0.05\right)$, so relationships between this and the other variables were assessed using Spearman's rank-order correlation coefficients $\left(r_{s}\right)$. Correlations are presented with $95 \%$ confidence intervals $(\mathrm{CI})$ and $P$ values. To further assess the utility of PFO as a performance parameter that can be measured during routine physiological profiling assessments, a stepwise linear regression was performed in $R$ using the 'stepAIC' function. The dependent variable was 30-min TT performance $(W)$, while traditional performance profiling metrics and observed PFO $\left(\mathrm{g} \cdot \mathrm{min}^{-1}\right)$ were used as independent variables. The traditional profiling metrics were $\dot{\mathrm{VO}}_{2}$ peak $\left(\mathrm{mL} \mathrm{kg}^{-1} \cdot \mathrm{min}^{-1}\right)$, power at $4 \mathrm{mmol} \mathrm{L}^{-1}$ blood lactate concentration (W), and gross cycling efficiency (GE) at $165 \mathrm{~W}$ (\%). These variables were selected in line with previously established models of endurance performance (Joyner and
Coyle 2008; McLaughlin et al. 2010). The stepwise model selection process involved forward inclusion and backward elimination to identify the most predictive and parsimonious model, using the Akaike information criterion (AIC). We then compared the optimal model resulting from the stepwise procedure (which contained PFO as a predictor), with a model only containing traditional profiling metrics (i.e. that containing $\dot{\mathrm{VO}}_{2}$ peak, power at $4 \mathrm{mmol} \mathrm{L}^{-1}$ blood lactate concentration, and GE at $165 \mathrm{~W}$ ). As these two models were not nested, this was done with an encompassing test (i.e. against the overall model containing all four independent variables), using the 'Imtest' $R$ package. Model assumptions were checked using the 'performance' $R$ package. For all models, standardised (beta) regression coefficients were obtained using the 'lm.beta' $R$ package. Analyses were performed in $R$ (version 4.4.0) with RStudio (version 1.1463). Statistical significance was inferred when $P \leq 0.05$.

\section{Results}

The PFO during fasted, incremental cycling was $0.58 \pm 0.28{\mathrm{~g} \cdot \mathrm{min}^{-1}}^{-1}$ using observed values (range $0.32-1.00 \mathrm{~g} \cdot \mathrm{min}^{-1}$ ), and $0.58 \pm 0.28 \mathrm{~g} \cdot \mathrm{min}^{-1}$ using modelled values (range $0.31-1.07 \mathrm{~g} \cdot \mathrm{min}^{-1}, P=0.46$ ). Selected responses at observed PFO are shown in Table 1. Both observed and modelled PFO values were significantly greater than average fat oxidation during 2-h of fed-state, constant-load cycling at $80 \%$ of $\mathrm{VT}_{1}$ was $0.32 \pm 0.16 \mathrm{~g} \cdot \mathrm{min}^{-1}$ (range $0.16-0.71 \mathrm{~g} \cdot \mathrm{min}^{-1}$, Fig. 1, both $P<0.001$ ). Vastus lateralis CD36 abundance was $16.8 \pm 12.6 \mu \mathrm{g}^{-\mathrm{g}^{-1}}$ muscle protein (range $6.3-52.0 \mu \mathrm{g} \cdot \mathrm{g}^{-1}$ muscle protein). Vastus lateralis CS activity was $69.2 \pm 26.0 \mu \mathrm{mol} \cdot \mathrm{min}^{-1} \cdot \mathrm{g}^{-1}$ muscle protein (range 41.3-132.3 $\mu \mathrm{mol} \cdot \mathrm{min}^{-1} \cdot \mathrm{g}^{-1}$ muscle protein). Power output during the $30-$ min TT was $251 \pm 51 \mathrm{~W}$ (range $196-367 \mathrm{~W}$ ), or $3.2 \pm 0.6 \mathrm{~W} \cdot \mathrm{kg}^{-1}$ body mass (range 2.5-4.9 $\mathrm{W} \cdot \mathrm{kg}^{-1}$ ). Linear relationships between outcome measures are reported in Table 2. As relationships between PFO estimated according to observed and modelled values and other outcome measures were similar, observed

Table 1 Selected responses measured at the observed peak fat oxidation rate

\begin{tabular}{|c|c|}
\hline Variable & Mean \pm SD \\
\hline$\dot{\mathrm{V}} \mathrm{O}_{2}\left(\mathrm{~L} \cdot \mathrm{min}^{-1}\right)$ & $1.98 \pm 0.64$ \\
\hline$\dot{\mathrm{V}}_{2}(\%$ of peak $)$ & $46 \pm 10$ \\
\hline$\dot{\mathrm{V} C O}{ }_{2}\left(\mathrm{~L} \cdot \mathrm{min}^{-1}\right)$ & $1.63 \pm 0.54$ \\
\hline $\mathrm{PetCO}_{2}(\mathrm{mmHg})$ & $36.4 \pm 2.2$ \\
\hline$\dot{\mathrm{V}}_{\mathrm{E}} \dot{\mathrm{V}}_{\mathrm{CO}_{2}}^{-1}$ & $24.9 \pm 2.1$ \\
\hline Blood $\left[\mathrm{La}^{-}\right]\left(\mathrm{mmol}^{-1} \mathrm{~L}^{-1}\right)$ & $1.4 \pm 0.4$ \\
\hline Cadence (revs $\min ^{-1}$ ) & $82 \pm 4$ \\
\hline
\end{tabular}




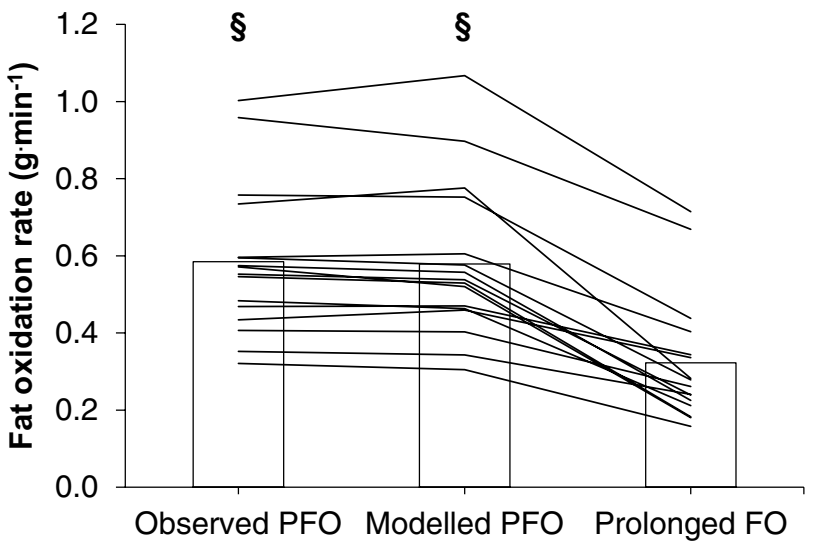

Fig. 1 Comparison of peak fat oxidation during fasted incremental cycling estimated using observed and modelled values, and average fat oxidation during 2 -h of fed-state cycling at $80 \%$ of the first ventilatory threshold. Bars indicate group mean and lines indicate individual responses. ' $\S$ ' indicates $P<0.001$ vs. average fat oxidation during 2-h of fed-state cycling at $80 \%$ of the first ventilatory threshold
PFO values are referred to herein. Relationships between observed PFO and outcome measures are shown graphically in Fig. 2.

The stepwise regression removed GE and identified the model containing $\dot{\mathrm{VO}} 2$ peak, power at $4 \mathrm{mmol} \mathrm{L}^{-1}$ blood lactate concentration, and observed PFO as the most predictive and parsimonious of pre-loaded 30-min TT performance (adjusted $R^{2}=0.900, \mathrm{AIC}=86.41, P<0.001$ ), explaining $90.0 \%$ of the variation (Table 3$)$. The traditional model $\left(\mathrm{VO}_{2}\right.$ peak, power at $4 \mathrm{mmol} \mathrm{L}^{-1}$ blood lactate concentration, and $\mathrm{GE}$ at $165 \mathrm{~W}$ ) explained $87.7 \%$ of the variation in pre-loaded 30 -min TT performance (adjusted $R^{2}=0.877, \mathrm{AIC}=90.18$, $P<0.001)$. The overall model containing all four independent variables explained $90.3 \%$ of the variation in $30-\mathrm{min}$ TT performance (adjusted $R^{2}=0.903, \mathrm{AIC}=86.52, P<0.001$ ). The encompassing test revealed the stepwise model did not perform significantly differently compared to the overall model containing all four independent variables $(P=0.27)$, but approached significance $(P=0.06)$ when comparing the traditional model to the overall model.

Table 2 Bivariate associations between outcome measures in this study

\begin{tabular}{|c|c|c|c|c|c|}
\hline & Prolonged FO & CD36 abundance & CS activity & TT (W) & $\mathrm{TT}\left(\mathrm{W} \cdot \mathrm{kg}^{-1}\right)$ \\
\hline $\begin{array}{l}\text { Incremental PFO (observed) } \\
\left(\mathrm{g} \cdot \mathrm{min}^{-1}\right)\end{array}$ & $\begin{array}{l}r=0.83 \\
(0.57,0.94) \\
P<0.001 \\
N=16\end{array}$ & $\begin{array}{l}r_{s}=0.68 \\
(0.31,1.10) \\
P=0.01 \\
N=13\end{array}$ & $\begin{array}{l}r=0.84 \\
(0.58,0.95) \\
P<0.001 \\
N=15\end{array}$ & $\begin{array}{l}r=0.76 \\
(0.40,0.91) \\
P=0.001 \\
N=15\end{array}$ & $\begin{array}{l}r=0.62 \\
(0.16,0.86) \\
P=0.01 \\
N=15\end{array}$ \\
\hline $\begin{array}{l}\text { Incremental PFO (modelled) } \\
\left(\mathrm{g} \cdot \mathrm{min}^{-1}\right)\end{array}$ & $\begin{array}{l}r=0.84 \\
(0.59,0.94) \\
P<0.001 \\
N=16\end{array}$ & $\begin{array}{l}r_{s}=0.59 \\
(0.22,1.11) \\
P=0.03 \\
N=13\end{array}$ & $\begin{array}{l}r=0.83 \\
(0.56,0.94) \\
P<0.001 \\
N=15\end{array}$ & $\begin{array}{l}r=0.75 \\
(0.38,0.91) \\
P=0.001 \\
N=15\end{array}$ & $\begin{array}{l}r=0.61 \\
(0.14,0.86) \\
P=0.02 \\
N=15\end{array}$ \\
\hline $\begin{array}{l}\text { Incremental PFO } \\
\text { (observed) } \\
\left(\mathrm{g} \cdot \mathrm{min}^{-1} \mathrm{~kg}^{-1} \mathrm{BM}\right)\end{array}$ & $\begin{array}{l}r=0.84 \\
(0.59,0.94) \\
P<0.001 \\
N=16\end{array}$ & $\begin{array}{l}r_{s}=0.66 \\
(0.20,1.11) \\
P=0.02 \\
N=13\end{array}$ & $\begin{array}{l}r=0.89 \\
(0.69,0.96) \\
P<0.001 \\
N=15\end{array}$ & $\begin{array}{l}r=0.69 \\
(0.27,0.89) \\
P=0.005 \\
N=15\end{array}$ & $\begin{array}{l}r=0.71 \\
(0.32,0.90) \\
P=0.003 \\
N=15\end{array}$ \\
\hline Prolonged FO & & $\begin{array}{l}r_{s}=0.21 \\
(-0.47,1.04) \\
P=0.48 \\
N=13\end{array}$ & $\begin{array}{l}r=0.90 \\
(0.73,0.96) \\
P<0.001 \\
N=16\end{array}$ & $\begin{array}{l}r=0.58 \\
(0.12,0.84) \\
P=0.02 \\
N=16\end{array}$ & $\begin{array}{l}r=0.56 \\
(0.08,0.82) \\
P=0.03 \\
N=16\end{array}$ \\
\hline CD36 abundance & & & $\begin{array}{l}r_{s}=0.24 \\
(-0.46,0.86) \\
P=0.43 \\
N=13\end{array}$ & $\begin{array}{l}r_{s}=0.61 \\
(-0.02,1.14) \\
P=0.04 \\
N=12\end{array}$ & $\begin{array}{l}r_{s}=0.22 \\
(-0.37,1.00) \\
P=0.49 \\
N=12\end{array}$ \\
\hline CS activity & & & & $\begin{array}{l}r=0.53 \\
(0.03,0.82) \\
P=0.04 \\
N=15\end{array}$ & $\begin{array}{l}r=0.62 \\
(0.15,0.86) \\
P=0.01 \\
N=15\end{array}$ \\
\hline $\mathrm{TT}(\mathrm{W})$ & & & & & $\begin{array}{l}r=0.86 \\
(0.63,0.95) \\
P<0.001 \\
N=16\end{array}$ \\
\hline
\end{tabular}

$B M$ body mass, $C S$ vastus lateralis citrate synthase activity expressed per unit of muscle protein, CD36 vastus lateralis cluster of differentiation 36 abundance expressed per unit of muscle protein, $F O$ whole-body fat oxidation rate during $2 \mathrm{~h}$ of fed-state constant-load cycling at the first ventilatory threshold with carbohydrate feeding expressed in $\mathrm{g} \cdot \mathrm{min}^{-1}, P F O$ peak whole-body fat oxidation rate during incremental cycling expressed in $\mathrm{g} \cdot \mathrm{min}^{-1}, T T$ average power during a 30-min maximal-effort time-trial preceded by $2 \mathrm{~h}$ of constant-load cycling at the first ventilatory threshold 
(a)

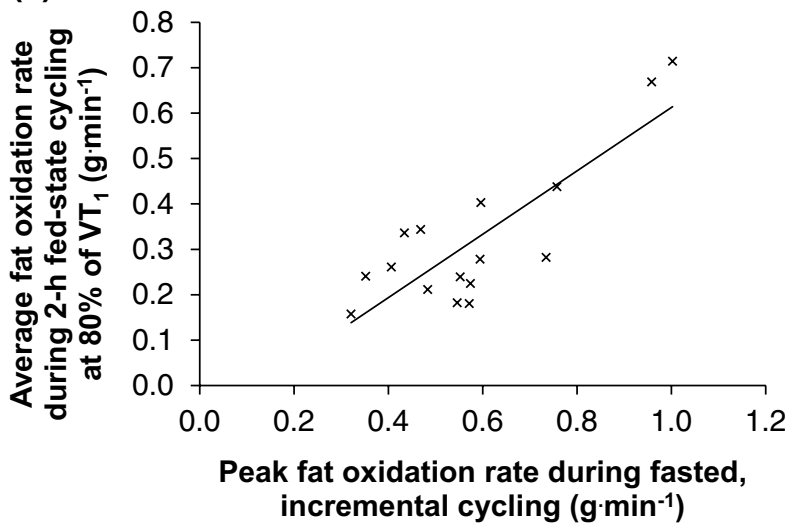

(c)

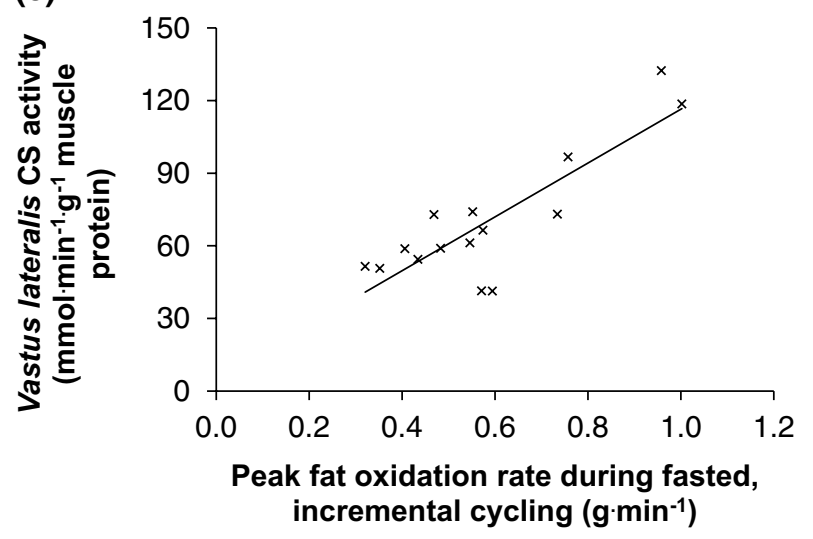

(b)

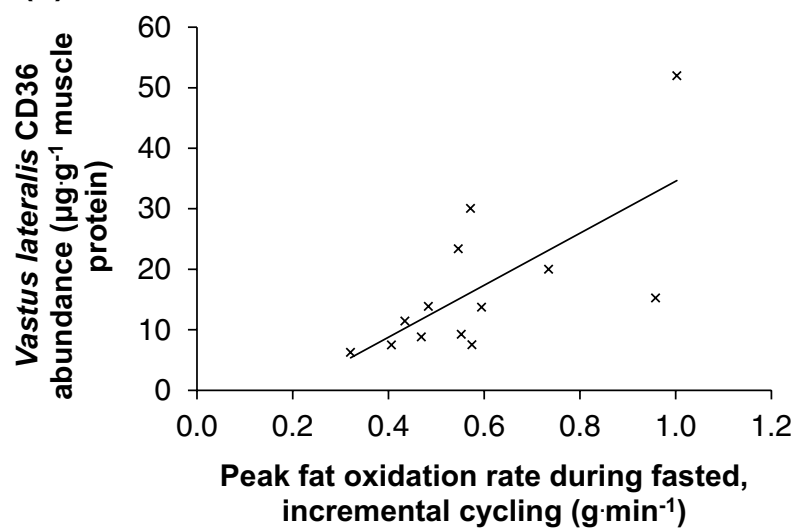

(d)

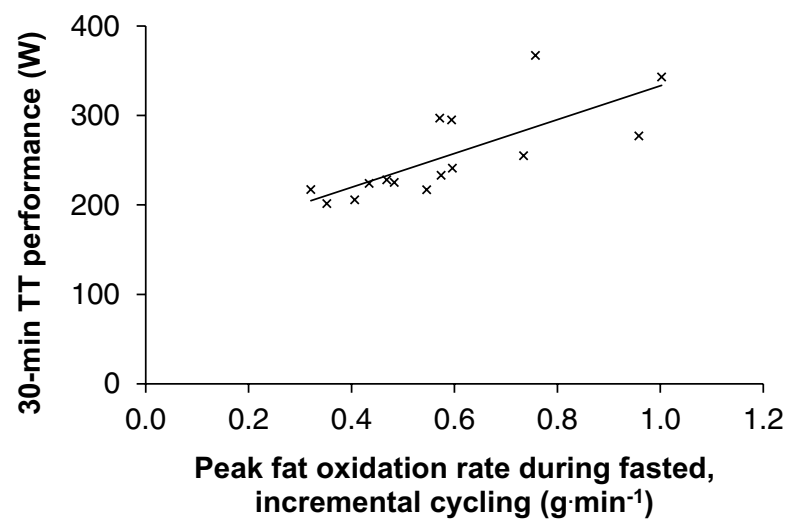

(e)

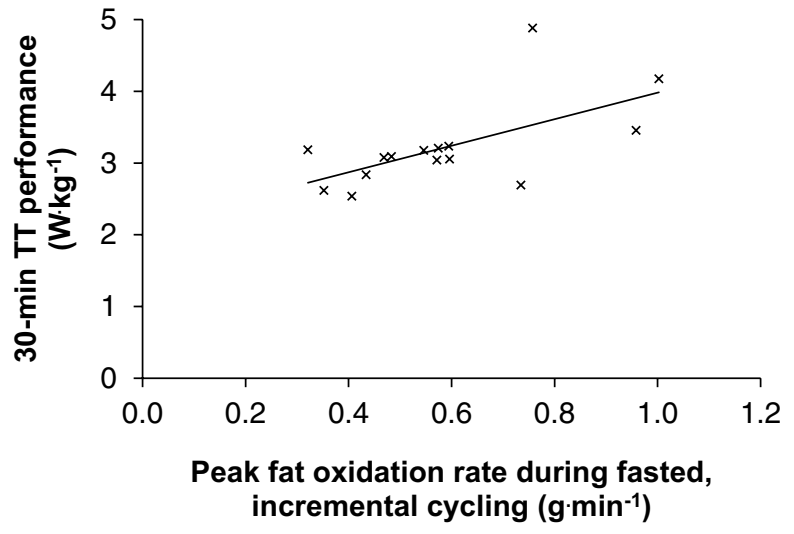

Fig. 2 Relationships between peak fat oxidation during fasted, incremental cycling using observed values and a average fat oxidation during 2-h of fed-state cycling at $80 \%$ of the first ventilatory threshold $\left(\mathrm{VT}_{1}\right)$, b vastus lateralis $\mathrm{CD} 36$ abundance, $\mathbf{c}$ vastus lateralis $\mathrm{CS}$

\section{Discussion}

The aim of the present investigation was to assess relationships between PFO measured during fasted incremental activity, d 30-min time-trial performance expressed in Watts, and e 30-min time-trial performance expressed in Watts per kilogram of body mass

cycling, skeletal muscle CD36 abundance, endurance performance, and fat oxidation during prolonged moderate-intensity exercise in the fed-state in endurancetrained males. The main findings were that: (i) PFO had 
Table 3 Summary of regression models of pre-loaded 30-min time-trial performance $(\mathrm{W})$

\begin{tabular}{|c|c|c|c|c|c|c|}
\hline Descriptor & AIC & Adjusted $R^{2}$ & $P$ & Input variable & $\begin{array}{l}\text { Unstandard- } \\
\text { ised coefficient }\end{array}$ & $\begin{array}{l}\text { Standardised } \\
\text { coefficient }\end{array}$ \\
\hline \multirow[t]{4}{*}{ Overall } & \multirow[t]{4}{*}{86.52} & \multirow[t]{4}{*}{0.903} & \multirow[t]{4}{*}{$<0.001$} & $\mathrm{VO}_{2}$ peak & 3.109 & 0.460 \\
\hline & & & & Power at $4 \mathrm{mmol} \mathrm{L}^{-1}$ & 0.395 & 0.419 \\
\hline & & & & GE & 3.729 & 0.102 \\
\hline & & & & PFO & 59.057 & 0.236 \\
\hline \multirow[t]{3}{*}{ Traditional } & \multirow[t]{3}{*}{90.18} & \multirow[t]{3}{*}{0.877} & \multirow[t]{3}{*}{$<0.001$} & $\dot{\mathrm{VO}}_{2}$ peak & 3.481 & 0.497 \\
\hline & & & & Power at $4 \mathrm{mmol} \mathrm{L}^{-1}$ & 0.519 & 0.558 \\
\hline & & & & GE & 3.578 & 0.096 \\
\hline \multirow[t]{3}{*}{ Stepwise } & \multirow[t]{3}{*}{86.41} & \multirow[t]{3}{*}{0.900} & \multirow[t]{3}{*}{$<0.001$} & $\dot{\mathbf{V}} \mathbf{O}_{2}$ peak & 2.817 & 0.417 \\
\hline & & & & Power at $4 \mathrm{mmol}^{-1}$ & 0.405 & 0.430 \\
\hline & & & & PFO & 61.878 & 0.248 \\
\hline
\end{tabular}

Independent variables used in the model were $\mathrm{VO}_{2}$ peak $\left(\mathrm{mL} \mathrm{kg}^{-1} \cdot \mathrm{min}^{-1}\right)$, power at $4 \mathrm{mmol} \mathrm{L}^{-1}$ blood lactate concentration (W), gross efficiency at $165 \mathrm{~W}(\mathrm{GE}, \%)$, and observed peak fat oxidation rate (PFO, $\left.\mathrm{g} \cdot \mathrm{min}^{-1}\right)$. The traditional model did not use observed PFO. The bold model has the lowest Akaike information criterion (AIC), and was, therefore, selected as the best and most parsimonious model fit moderate-to-strong associations with vastus lateralis CD36 abundance and CS activity, (ii) PFO had moderateto-strong associations with 30-min TT performance preceded by $2 \mathrm{~h}$ of moderate-intensity cycling, (iii) addition of PFO to a traditional model of endurance containing $\dot{V}$ $\mathrm{O}_{2}$ peak, power at $4 \mathrm{mmol} \mathrm{L}^{-1}$ blood lactate concentration, and GE explained an additional $\sim 2.6 \%$ of variation in 30-min TT performance, with standardised coefficients indicating that $\mathrm{PFO}$ contributed more than twice as much to the model as GE, and (iv) PFO had a strong association with whole-body fat oxidation during two-hours of moderate-intensity, fed-state cycling with $\mathrm{CHO}$ feeding.

In line with our hypotheses, PFO was significantly associated with vastus lateralis CD36 abundance $\left(r_{s}=0.68\right.$, 95\% CI $0.31,1.10, P=0.01)$ and CS activity $(r=0.84,95 \%$ CI $0.58,0.95, P<0.001)$. Previous research has observed relationships between PFO and CS activity and other mitochondrial markers, such as mitochondrial volume density and OXPHOS subunit protein content (Nordby et al. 2006; Stisen et al. 2006; Dandanell et al. 2018; Shaw et al. 2020). The positive association between PFO and vastus lateralis CD36 abundance in the present investigation is to our knowledge a novel observation (Table 2), and adds to recent research reporting associations between $\mathrm{PFO}$ and abundance of FABPpm and CPT1B (Chrzanowski-Smith et al. 2021). It is likely the relationship between PFO and whole-muscle CD36 abundance is explained by capacity for CD36 translocation, given CD36 translocates to the sarcolemmal (Bradley et al. 2012) and mitochondrial (Holloway et al. 2006) membranes during exercise to facilitate fatty acid import. Indeed, whole-body fat oxidation rates increased over time during 120 min cycling at $60 \% \dot{\mathrm{VO}}_{2}$ peak in a trial in which CD36 abundance in whole-muscle homogenate remained unchanged but CD36 translocation was observed (Bradley et al. 2012).
Interestingly, no relationship was observed between vastus lateralis CD36 abundance and whole-body fat oxidation during 2-h fed-state cycling at $80 \%$ of $\mathrm{VT}_{1}$ with $\mathrm{CHO}$ feeding $\left(r_{s}=0.21,95 \% \mathrm{CI}-0.47,1.04, P=0.48\right)$, which may suggest CD36 is relatively less determining of fat oxidation during exercise in these conditions. The high rate of $\mathrm{CHO}$ feeding during the prolonged moderate-intensity exercise likely suppressed plasma non-esterified fatty acid (NEFA) rate of appearance and circulating concentrations (Wallis et al. 2005; Stellingwerff et al. 2007), plausibly reducing the potential for an individual's capacity for fatty acid import across the sarcolemmal membrane to influence substrate oxidation during exercise. Fat oxidation during fed-state cycling with $\mathrm{CHO}$ feeding was strongly related to vastus lateralis $\mathrm{CS}$ activity ( $r=0.90,95 \%$ CI $0.73,0.96, P<0.001$ ), which suggests fatty acid metabolism in these circumstances is related to mitochondrial protein content (Larsen et al. 2012).

Our observation that PFO was associated with 30-min TT performance preceded by $2 \mathrm{~h}$ of moderate-intensity cycling may support its measurement during routine physiological profiling assessments (Maunder et al. 2018b). Addition of PFO to a model of 30-min TT performance containing $\mathrm{VO}_{2}$ peak, power at $4 \mathrm{mmol} \mathrm{L}^{-1}$ blood lactate concentration, and $\mathrm{GE}$ at $165 \mathrm{~W}$ explained an additional $2.6 \%$ of variation (adjusted $R^{2} 0.903$ vs. 0.877 ), and the stepwise model selection process removed GE and included PFO (adjusted $R^{2}$ 0.900). The same inferences were observed when PFO was expressed relative to body mass, only the extra variation explained was $\sim 1 \%$ (data not shown). The contribution of PFO to these performance models is further substantiated by the standardised coefficients (Table 3). We should, however, acknowledge that the variation in body mass within our sample $(68-98 \mathrm{~kg})$, and therefore contribution made by resting metabolic rate to energy expenditure, may have influenced the apparent lack of contribution made by GE to model fit. 
Previously, significant associations between finishing time in an Ironman triathlon and PFO during an incremental test have been observed (Frandsen et al. 2017; Vest et al. 2019), though in these studies the relationships with performance $(r=0.35-0.47, P<0.05)$ were weaker than in the present investigation. These disparities could be related to the fieldbased, multi-sport, longer duration Ironman triathlons and lack between-subject pre- and during-competition controls used in previous work (Frandsen et al. 2017; Vest et al. 2019).

Mechanistically, utilising fatty acids to support energy metabolism during prior moderate-intensity cycling may have facilitated subsequent 30-min TT performance via effects on glycogen availability at onset of the TT. Muscle glycogen is progressively depleted during prolonged exercise (Bergström et al. 1967), and glycogen phosphorylase activation (Hespel and Richter 1992), and consequently glycogenolysis (Hargreaves et al. 1995), is related to glycogen availability. Therefore, preserving muscle glycogen during the initial 2-h of moderate-intensity cycling via fatty acid utilisation may have helped facilitate high rates of glycogenolysis, and therefore, work output, during the TT. This explanation remains plausible despite the absence of a relationship between vastus lateralis $\mathrm{CD} 36$ abundance and prolonged fed-state fat oxidation, as fat oxidation in this metabolic milieu may have been driven by other steps in the fatty acid metabolism pathway that are also associated with PFO during fasted, incremental exercise, such as enzymes involved in $\beta$-oxidation and intramuscular triacylglycerol hydrolysis, or type I fibre percentage (Nordby et al. 2006; Stisen et al. 2006; Dandanell et al. 2018; Shaw et al. 2020). Indeed, positive associations were observed between PFO and prolonged fed-state fat oxidation ( $r=0.83,95 \%$ CI 0.57 , $0.94, P<0.01)$, and between prolonged fed-state fat oxidation and 30-min TT performance $(r=0.58,95 \%$ CI 0.12 , $0.84, P=0.02)$. However, it should also be acknowledged that $\mathrm{CHO}$ ingestion across the two meals prior to the TT was relatively low $\left(2.5-3.0 \mathrm{~g} \mathrm{~kg}^{-1}\right)$. If $\mathrm{CHO}$ ingestion during this period was greater, the presumably greater pre-trial glycogen storage may have reduced the relevance of fat oxidation during the prolonged exercise prior to the TT. Future research could investigate the implications of fat oxidation during prolonged exercise for subsequent performance in a similar model with more aggressive pre-trial $\mathrm{CHO}$ feeding.

It is possible the relationship between PFO and pre-loaded 30-min TT performance was not causal, and that greater mitochondrial protein content supports both independently. Indeed, vastus lateralis CS activity was positively correlated with PFO and pre-loaded 30-min TT performance (Table 2). Nevertheless, given invasive measures of mitochondrial protein content are generally not feasible in applied settings, our observation that addition of PFO to a model of pre-loaded 30 -min TT performance explained an additional $\sim 2.6 \%$ of variation above that explained by the traditional non-invasive parameters indicates PFO may be a worthwhile assessment parameter in applied settings. Whilst this $\sim 2.6 \%$ extra variation is not extensive, as PFO can be easily estimated during routine physiological profiling assessments without further equipment, time, or protocols beyond what is adopted routinely (Maunder et al. 2018b), its inclusion may be justified in some applied sport settings where small differences in performance can determine success and failure. Indeed, these observations provide data with which applied practitioners can make decisions regarding the relevance of estimating PFO in their specific context.

A further observation supporting estimation of PFO in routine physiological profiling assessments is the significant, strong association between PFO and whole-body fat oxidation during fed-state, prolonged moderate-intensity cycling with CHO feeding $(r=0.83,95 \%$ CI $0.57,0.94, P<0.001)$. Routine physiological profiling assessments are commonly conducted after an overnight fast for ease of repetition in follow-up (Maunder et al. 2018b). Given that whole-body fat oxidation rates are greater during exercise in the fasted compared to fed state (Coyle et al. 1997; Horowitz et al. 1997; Bergman and Brooks 1999), and may increase over time during prolonged exercise (Ahlborg et al. 1974; Watt et al. 2002, 2006), whole-body fat oxidation rates during fasted incremental exercise may not be readily transferable to the prolonged fed-state exercise that endurance athletes perform in training and competition. However, the present data suggest PFO measured during fasted incremental cycling can distinguish athletes likely to exhibit higher or lower whole-body fat oxidation rates during prolonged fed-state exercise with $\mathrm{CHO}$ feeding (Table 2). These data, therefore, support inclusion of PFO estimates in routine physiological profiling assessments with endurance athletes interested in substrate oxidation responses during subsequent training and competition. It should be acknowledged here that serial measurement of PFO during routine physiological profiling requires careful control of protocol design and acute diet and exercise status (Amaro-Gahete et al. 2019).

In summary, PFO measured during fasted, incremental cycling had moderate-to-strong associations with vastus lateralis CD36 abundance, CS activity, pre-loaded 30-min TT performance, and whole-body fat oxidation rates during prolonged fed-state cycling with $\mathrm{CHO}$ feeding in endurancetrained males. Furthermore, addition of PFO to a model containing $\mathrm{VO}_{2}$ peak, power at $4 \mathrm{mmol} \mathrm{L}^{-1}$ blood lactate concentration, and GE explained an additional $\sim 2.6 \%$ of the variation in pre-loaded 30-min TT performance. These data, therefore, support the inclusion of non-invasive PFO estimates in routine physiological profiling assessments with endurance athletes if insight into skeletal muscle parameters, endurance performance, and/or substrate oxidation responses to subsequent training and competition is sought. 
Acknowledgements The authors would like to acknowledge all the participants involved in this study.

Author contributions EM, AEK, DJP, and GAW conceived and designed the research. EM, WLC, CMW, MJB, and WBL conducted experiments and collected the data. EM and TS analysed the data. EM drafted the manuscript. All authors read, revised, and approved the manuscript.

Funding E.M. was supported by an Education New Zealand International Doctoral Research Scholarship. No other sources of funding were used in the preparation of this manuscript.

Availability of data and materials Data are available from the corresponding author upon reasonable request.

Code availability Code is available upon reasonable request.

\section{Declarations}

Conflict of interest The authors declare no competing interests associated with this manuscript.

Ethics approval The Auckland University of Technology Ethics Committee approved all procedures (19/146).

Consent to participate All participants provided written informed consent.

Consent for publication All participants were informed of the intention to publish data generated in this study prior to providing informed consent.

\section{References}

Achten J, Gleeson M, Jeukendrup AE (2002) Determination of exercise intensity that elicits maximal fat oxidation. Med Sci Sport Exerc 34:92-97

Ahlborg G, Felig P, Hagenfeldt L et al (1974) Substrate turnover during prolonged exercise in man. J Clin Invest 53:1080-1090

Amaro-Gahete FJ, Sanchez-Delgado G, Jurado-Fasoli L et al (2019) Assessment of maximal fat oxidation during exercise: a systematic review. Scand J Med Sci Sport 29:910-921

Bergman BC, Brooks GA (1999) Respiratory gas-exchange ratios during graded exercise in fed and fasted trained and untrained men. J Appl Physiol 86:479-487

Bergström J, Hermansen L, Hultman E, Saltin B (1967) Diet, muscle glycogen and physical performance. Acta Physiol Scand $71: 140-150$

Bradley NS, Snook LA, Jain SS et al (2012) Acute endurance exercise increases plasma membrane fatty acid transport proteins in rat and human skeletal muscle. Am J Physiol 302:E183-E189. https://doi. org/10.1152/ajpendo.00254.2011

Chrzanowski-Smith OJ, Edinburgh RM, Smith E et al (2021) Resting skeletal muscle ATGL and CPT1b are associated with peak fat oxidation rates in men and women but do not explain observed sex-differences. Exp Physiol. https://doi.org/10.1113/EP089431

Coyle EF, Jeukendrup AE, Wagenmakers AJM, Saris WHM (1997) Fatty acid oxidation is directly regulated by carbohydrate metabolism during exercise. Am J Physiol 273:E268-E275
Dandanell S, Meinlid-Lundby A, Andersen AB et al (2018) Determinants of maximal whole-body fat oxidation in elite cross-country skiers : Role of skeletal muscle mitochondria. Scand J Med Sci Sport 28:2494-2504. https://doi.org/10.1111/sms.13298

Frandsen J, Vest S, Larsen S et al (2017) Maximal fat oxidation is related to performance in an Ironman triathlon. Int J Sports Med 38:975-982. https://doi.org/10.1055/s-0043-117178

Frandsen J, Vest SD, Ritz C et al (2019) Plasma free fatty acid concentration is closely tied to whole body peak fat oxidation rate during repeated exercise. J Appl Physiol 126:1563-1571

Hargreaves M, McConell G, Proietto J (1995) Influence of muscle glycogen on glycogenolysis and glucose uptake during exercise in humans. J Appl Physiol 78:288-292

Hayot M, Michaud A, Koechlin C et al (2005) Skeletal muscle microbiopsy: a validation study of a minimally invasive technique. Eur Respir J 25:431-440. https://doi.org/10.1183/09031936.05.00053 404

Hespel P, Richter EA (1992) Mechanism linking glycogen concentration and glycogenolytic rate in perfused contracting rat skeletal muscle. Biochem J 284:777-780. https://doi.org/10.1042/bj284 0777

Holloway GP, Bezaire V, Heigenhauser GJF et al (2006) Mitochondrial long chain fatty acid oxidation, fatty acid translocase/CD36 content and carnitine palmitoyltransferase I activity in human skeletal muscle during aerobic exercise. J Physiol 571:201-210. https:// doi.org/10.1113/jphysiol.2005.102178

Horowitz JF, Mora-Rodriguez R, Byerley LO, Coyle EF (1997) Lipolytic suppression following carbohydrate ingestion limits fat oxidation during exercise. Am J Physiol 273:E768-E775. https://doi. org/10.1097/00005768-199605001-00443

Jamnick NA, Botella J, Pyne DB, Bishop DJ (2018) Manipulating graded exercise test variables affects the validity of the lactate threshold and $\mathrm{VO}_{2}$ peak. PLoS One 13:1-21. https://doi.org/10. 1371/journal.pone.0199794

Jeukendrup AE, Wallis GA (2005) Measurement of substrate oxidation during exercise by means of gas exchange measurements. Int $\mathrm{J}$ Sports Med 26:S28-S37. https://doi.org/10.1055/s-2004-830512

Joyner MJ, Coyle EF (2008) Endurance exercise performance: the physiology of champions. J Physiol 586:35-44

Larsen S, Nielsen J, Hansen CN et al (2012) Biomarkers of mitochondrial content in skeletal muscle of healthy young human subjects. J Physiol 590:3349-3360. https://doi.org/10.1113/jphysiol.2012. 230185

Lucía A, Hoyos J, Pérez M, Chicharro JL (2000) Heart rate and performance parameters in elite cyclists: a longitudinal study. Med Sci Sports Exerc 32:1777-1782. https://doi.org/10.1097/00005 768-200010000-00018

Maunder E, Kilding AE, Plews DJ (2018a) Substrate metabolism during Ironman Triathlon: different horses on the same courses. Sports Med 48:2219-2226. https://doi.org/10.1007/ s40279-018-0938-9

Maunder E, Plews DJ, Kilding AE (2018b) Contextualising maximal fat oxidation during exercise: determinants and normative values. Front Physiol 9:1-13. https://doi.org/10.3389/fphys.2018.00599

Maunder E, Plews DJ, Wallis GA et al (2021) Temperate performance and metabolic adaptations following endurance training performed under environmental heat stress. Physiol Rep 9:e14849. https://doi.org/10.14814/phy2.14849

McLaughlin JE, Howley ET, Bassett DR Jr et al (2010) Test of the classic model for predicting endurance running performance. Med Sci Sports Exerc 42:991-997

Moseley L, Jeukendrup AE (2001) The reliability of cycling efficiency. Med Sci Sports Exerc 33:621-627. https://doi.org/10.1097/00005 768-200104000-00017

Nordby P, Saltin B, Helge JW (2006) Whole-body fat oxidation determined by graded exercise and indirect calorimetry: a role for 
muscle oxidative capacity? Scand J Med Sci Sport 16:209-214. https://doi.org/10.1111/j.1600-0838.2005.00480.x

Rowlands DS, Hopkins WG (2002) Effects of high-fat and high-carbohydrate diets on metabolism and performance in cycling. Metabolism 51:678-690. https://doi.org/10.1053/meta.2002.32723

Shaw CS, Swinton C, Mcrae N et al (2020) Impact of exercise training status on the fiber type-specific abundance of proteins regulating intramuscular lipid metabolism. J Appl Physiol 128:379-389. https://doi.org/10.1152/japplphysiol.00797.2019

Stellingwerff T, Boon H, Gijsen AP et al (2007) Carbohydrate supplementation during prolonged cycling exercise spares muscle glycogen but does not affect intramyocellular lipid use. Pflugers Arch Eur J Physiol 454:635-647. https://doi.org/10.1007/ s00424-007-0236-0

Stisen AB, Stougaard O, Langfort J et al (2006) Maximal fat oxidation rates in endurance trained and untrained women. Eur J Appl Physiol 98:497-506. https://doi.org/10.1007/s00421-006-0290-x

Talanian JL, Holloway GP, Snook LA et al (2010) Exercise training increases sarcolemmal and mitochondrial fatty acid transport proteins in human skeletal muscle. Am J Physiol 299:E180-E188. https://doi.org/10.1152/ajpendo.00073.2010
Vest SD, Frandsen J, Larsen S, Dela F (2019) Peak fat oxidation is not independently related to Ironman performance in women. Int J Sports Med 39:916-923

Wallis GA, Rowlands DS, Shaw C et al (2005) Oxidation of combined ingestion of maltodextrins and fructose during exercise. Med Sci Sports Exerc 37:426-432. https://doi.org/10.1249/01.MSS.00001 55399.23358 .82

Watt MJ, Heigenhauser GJF, Dyck DJ, Spriet LL (2002) Intramuscular triacylglycerol, glycogen and acetyl group metabolism during $4 \mathrm{~h}$ of moderate exercise in man. J Physiol 541:969-978. https://doi. org/10.1113/jphysiol.2002.018820

Watt MJ, Holmes AG, Pinnamaneni SK et al (2006) Regulation of HSL serine phosphorylation in skeletal muscle and adipose tissue. Am J Physiol 290:E500-E508. https://doi.org/10.1152/ajpen do.00361.2005

Publisher's Note Springer Nature remains neutral with regard to jurisdictional claims in published maps and institutional affiliations. 